\title{
Infrastructure development in Africa's regions: investment trends and challenges
}

\author{
Alina Ibragimova ${ }^{1, *}$, Yan Wang ${ }^{2}$, and Michail Ivanov ${ }^{3}$ \\ ${ }^{1}$ Irkutsk National Research Technical University, 664074 Irkutsk, Russia \\ ${ }^{2}$ Belarus State Economic University, 220070 Minsk, Republic of Belarus \\ ${ }^{3}$ Bratsk state university, 665709 Bratsk, Russia
}

\begin{abstract}
The purpose of this work is to provide information on the development of the infrastructure of the African economy. The study provides statistics on African regions and industries. This article focuses on the forms of economic and social infrastructure, and directs to determine the share development infrastructural in Africa. The Africa has entered an era of devastating change this study shows that with the unfolding economic downturn in the northern economies that have traditionally dominated the global economy. The article provides empirical evidence on how the industrial sectors developed from an economic point of view. The authors believe that infrastructure affects output and productivity directly as a contribution to the production function of other sectors and as part of GDP formation. The article discusses the development of infrastructure for the period 1999-2019 without more detailed dynamics. It also does not explain the main topics developed by the authors. The work provides knowledge on how investments are developing in Africa, how industries have developed, and what is the role of each infrastructure sector in this development. It also shows how different areas of infrastructure work with different successes in creating new paths in the African economy.
\end{abstract}

\section{Introduction}

Infrastructure in its various forms plays a critical role in growth and development in Africa. Some types of infrastructure are important because they contribute to growth processes.

The may distinguish four different sets of economic infrastructure:

- Transport infrastructure (road, rail, ports and airports).

- Power generation.

- The information and communications (ICT) highway;

- The agricultural sector [1].

Such as water and sanitation predominantly delivers developmental outcomes the social infrastructure [2].

\footnotetext{
* Corresponding author: lanawhite@inbox.ru
} 
For example, these two sets of economic and social infrastructure interconnected. A transport system, which is distributed throughout the economy, has important development impact including to rural areas and to regions of relatively low income.

The former distinction is reflected in physical investments (for example, roads, power plants, ICT networks, irrigation networks, water treatment plants), whilst distinction the latter refers to the institutions in which the more serious infrastructure is embedded (for example, customs clearance procedures and sanitation system design). The Sub-Saharan Africa region visibly lags behind in infrastructure development to other country [3].

In considering the role of new and emerging economic actors in Africa's infrastructural sectors, it is necessary to understand two developments, which frame the expanding presence of these new actors in the African continent. The quest by external actors to secure access to Africa's raw materials has in some cases resulted in aid programs, which support the development of Africa's social infrastructure, also has major indirect implications for social infrastructure, as will be shown below. Improving agricultural productivity is complex and difficult. This will require the improvement and implementation of new methods, knowledge, skills and technologies [4].

You can also consider access to credit and find new approaches to overcome the risks and problems in agricultural development for them over the past few decades. The agricultural problem is too important for the Bank to be absent. Modern agriculture is largely market oriented and, therefore, is a private sector. The bank should approach this accordingly. Capable states should help create the necessary working conditions: invest in infrastructure, knowledge, research and skills, and provide a regulatory framework conducive to investment and growth [5].

It is necessary to balance the acceleration of economic growth by increasing the competitiveness of small farmers in areas where the potential return on investment is highest, with the guarantee that farmers and the rural poor can earn a living and have enough food. Long-term investments in soil and water management can increase the sustainability of cropping systems, especially for people in remote areas and those most at risk of climate change.

Africa needs a revolution based on smallholders, focused on staple foods, as well as traditional and non-traditional exports. Biofuels connect agricultural and energy markets [6].

Much attention is paid to the development of agriculture as the main infrastructure sector by industrial organizations such as the Food and Agriculture Organization and the International Fund for Agricultural Development, as well as by large banks of the country, such as the World Bank and the African Development Bank [5]. In this way, the African Development Bank can best enhance agricultural productivity by working in partnerships and contributing through infrastructure - markets, environmental measures, access roads, storage facilities, irrigation and other rural water supply programs — and improving the climate for private agricultural sector. Including efforts to strengthen management and regulation and improve access to credit for small and medium enterprises through appropriate intermediaries. The study is based on the fact that investment in infrastructure is the best way to increase Africa's competitiveness and potential in a number of productive sectors: agriculture, manufacturing, and industry. The African Development Bank is already paying more attention to infrastructure operations (Fig. 1 and Fig. 2), and in the near future, it could become a platform for demonstrating results. 
SHARE OF INFRASTRUCTURE INVESTMENT, 2015 YEAR

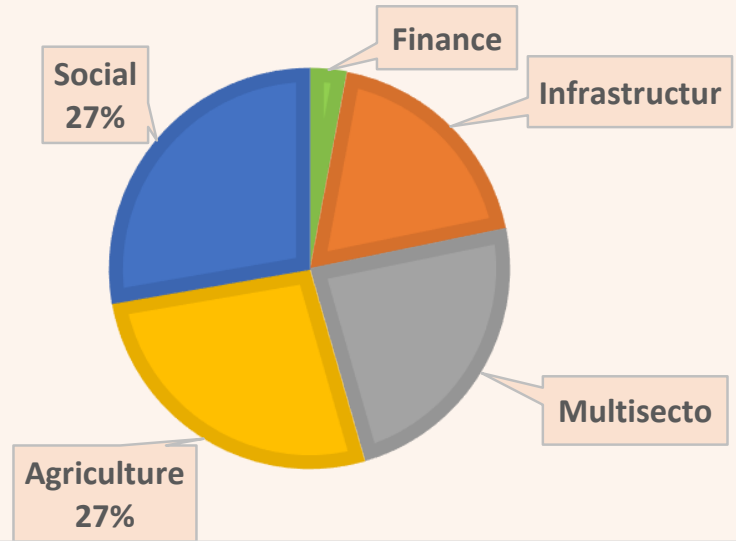

Fig. 1. Share of infrastructure investment, 2015 year

\section{SHARE OF INFRASTRUCTURE INVESTMENT, 2019 YEAR}

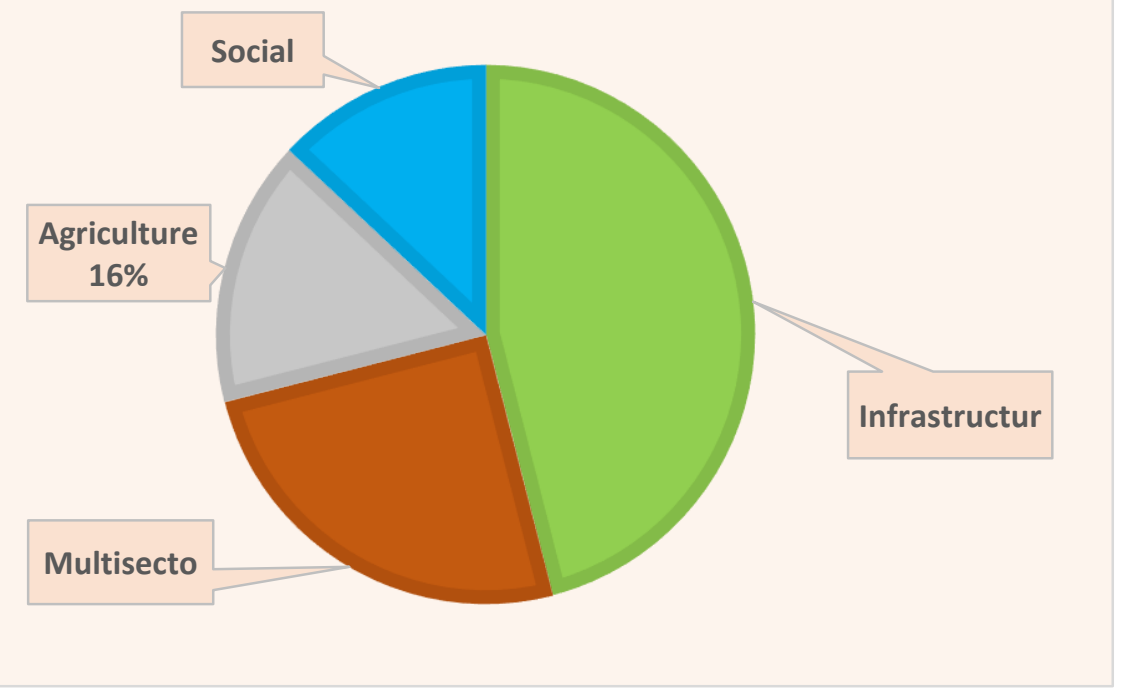

Fig. 2. Share of infrastructure investment, 2019 year

Based on the foregoing, we identified the problem of poor infrastructure for productivity, trade, growth and the most fundamental problem of poverty reduction in Africa.

Therefore, additional resources are needed to address the challenges to economic growth and regional economic integration. Investment in infrastructure should support the development of strong domestic markets, the integration of regional and subregional markets for intra-African trade, and the positioning of competitive Africa in global markets [7].

Beyond the low level of infrastructure, provision in aggregate is its poor distribution, particularly with respect to social infrastructure. The more typically nonexistent progress in the provision of social infrastructure has at best been slow [8]. There has been substantial progress in infrastructure provision contrasts with other low-income economies. The 
proportion of Africa's population having access to piped water, electricity and landline telephony is much lower in rural areas than in urban areas it show on the Fig. 3.

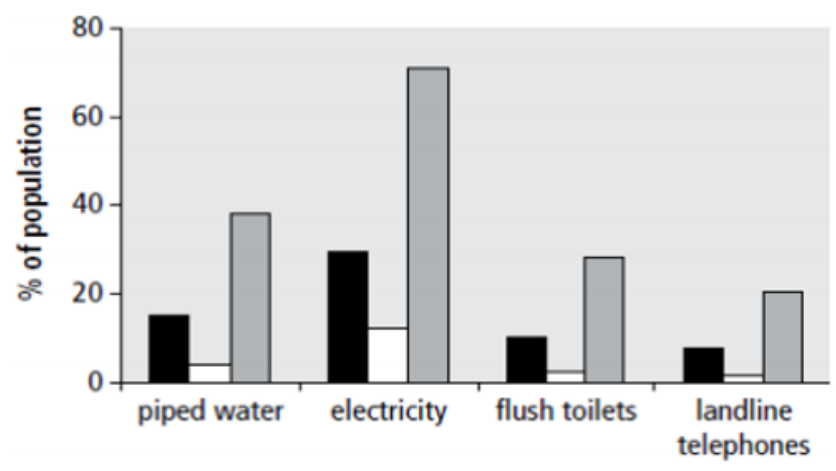

national $\square$ rural $\square$ urban

Fig. 3. The rural-urban divide in Africa's infrastructure

Africa's needs for both national and regional infrastructure are enormous: the investment needed to address Africa's major infrastructure weaknesses.

Africa needs these investments in order to grow fast enough to seriously affect poverty. However, aid infrastructure has recently been relatively ignored.

The development of infrastructure in Africa was almost $40 \%$ in 1999 to $24 \%$ in 2019, as spending in the social sector increased (Fig. 4).

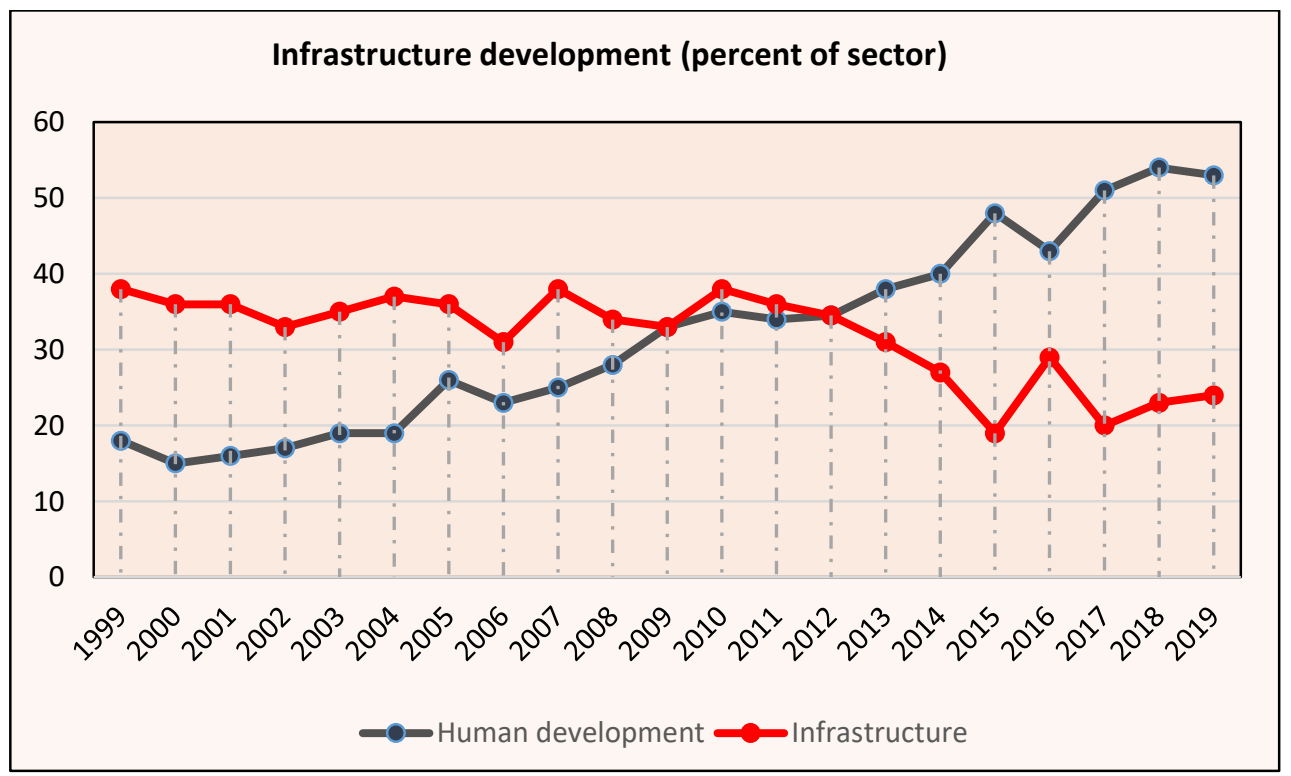

Fig. 4. Infrastructure development (percent of sector)

Increasing access to safe, reliable, and affordable energy is therefore an imperative for the Bank's work in infrastructure. This work should extend to the development of policy, to the institutional and regulatory framework that will encourage private sector participation, and to the capital investments in hard infrastructure. 
The second objective should be to identify the investments needed in soft infrastructure to facilitate trade and integration. For example, freight forwarders and couriers, drivers of international trade, are a critical complement to trade-facilitating infrastructure. However, transport providers in Africa must cope with a complex sequence of operations - from a field or plant to a warehouse, and then to land and sea transit, often across several borders before reaching their final destination [9]. The speed and effectiveness of supply chains does not only depend on harsh conditions. Infrastructure, but on a variety of public and private services: customs agents, customs brokers, freight forwarders, transport companies and banks. Inefficiency and corruption at the border entail serious costs for firms [10].

It is necessary to find some economic tools for implementation. In some cases, it may lead with concessional resources. In others, it may combine resources from both public and private windows, in still others; it may provide technical assistance and capacity building in support of regional infrastructure or public-private partnerships, opening new opportunities for improving the supply and quality of a broad range of services [11].

African producers and consumers are not only the poor availability and uneven distribution of economic and social infrastructure, but disadvantaged by its high cost. The costs are two to three times the levels to the costs faced by users in high-income economies.

However, the financial cost of infrastructural development is only one side of the coin. The skills required to envision, implement, strategize, implement and then operate often institutionally and technologically complex operations it is other side consists of the "soft" component of infrastructural development [12].

A much of the economic infrastructure requires cross-border cooperation further challenge confronting Africa's infrastructural development. This is particularly evident in the case of transport which suffer from externality challenges. This is particularly evident when suffer from classic externality challenges in the case of transport and power. There are some cases, where an individual user can pay for the costs of the infrastructure [13]. It is generally the case that no single user may be able to make enough use of the infrastructure to cover its costs. For example, a large power plant, or a point-to-point railway or pipeline between the commodity extraction site and the point of commodity export [14].

\section{Research methodology}

The article uses methods of mathematical analysis, synthesis, and computer modeling.

To undertake this study we identified conference papers published in the ADR site (https://www.afdb.org/enr) during 1999-2019. The network consists in 890 nodes and 1,644 links. We use NodeXL (Smith et al., 2010) as software packages for data processing and network visualization.

We received a number of measures to take into account the analysis of infrastructure development. We analyze the work of ADB Bank. In the process of research and analysis of this article, methods of comparative analysis, synthesis and processing of graphic data were used. The authors also conducted a comparative analysis of the share of infrastructure investment and provided statistics on African infrastructure development. The problems of infrastructure development were also identified [15].

The models for private participation vary from country to country, but five are most widespread (Fig. 5). 


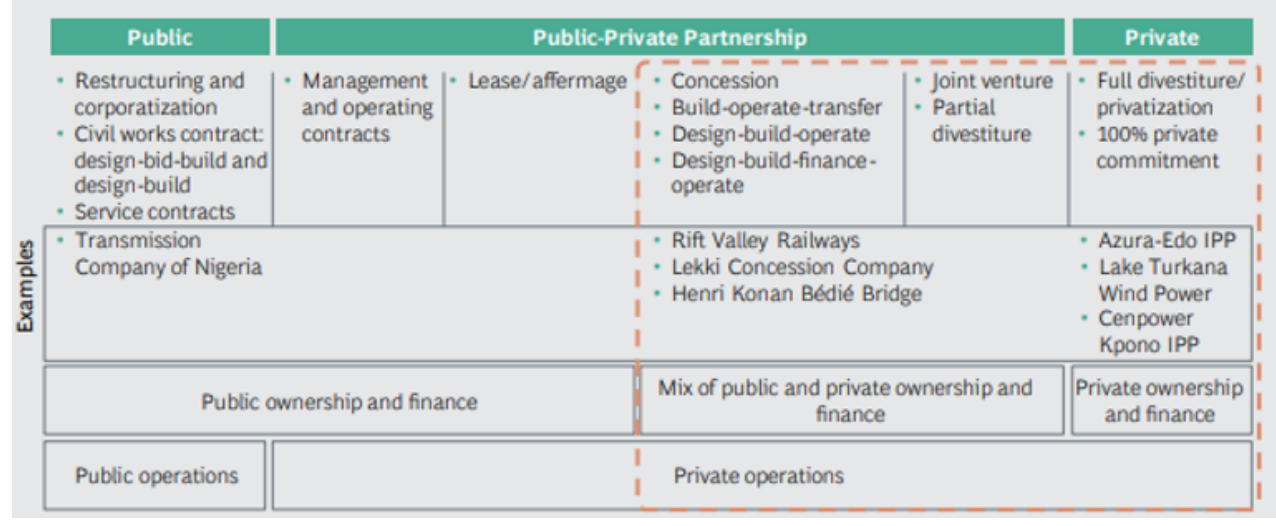

Fig. 5. The Range of Ways the Private Sector Can Invest in Infrastructure

Concession of existing infrastructure - primarily in the form of operation and maintenance agreements under which private operators maintain infrastructure and earn revenue. Projects developed and built by the government, and then sold or concessioned. The build-operatetransfer model, in which the private sector builds and operates an asset that becomes public sector property after an agreed period. A mix of public and private ownership and finance, usually with private operations co-owned. Assets that are $100 \%$ private-sector-owned and operated in perpetuity (as is the case with most ICT investments). The bank needs to create a fund to allocate amounts, regional investments, and provide incentives to countries to participate in these operations [16].

It is also advisable to create a solidarity fund that will be fully focused on promoting economic integration, especially through cross-border infrastructure based on continental and regional priorities. Africa together has foreign exchange reserves worth more than $\$ 300$ billion. Some foreign exchange reserves that provide a good rate of return can be invested in projects. As a tangible demonstration of their support for African integration, member countries need to take the initiative in establishing a fund. The experience of other countries, such as in the European Union, testifies to the long-term advantages of such a fund.

\section{Research results}

For sustainable economic growth and social progress is a capable state essential. Help is also of little use if there are no opportunities for project management and implementation. Such an opportunity is especially lacking in Africa. Therefore, the creation of capable states should be at the center of ADB's work [17].

The Bank needs more focus on its management work, which involved in a diverse range of management activities. His portfolio of management operations is small and has no clear direction. This requires a clear, more focused strategy.

As in all of its work, it is very important to respond to circumstances in the country, close coordination and complementarity with partners. To the order to determine a limited range of management measures where the Bank's capabilities are currently limited. Therefore, the near future it will have to make a clear choice where it can add real value and demonstrate superiority [18].

However, Africa is seriously lagging in higher education - with constraints on enrollment, mismatched worker skills and employer demands, a low retention rate for skilled workers, and limited ICT access and literacy (Fig. 6). 


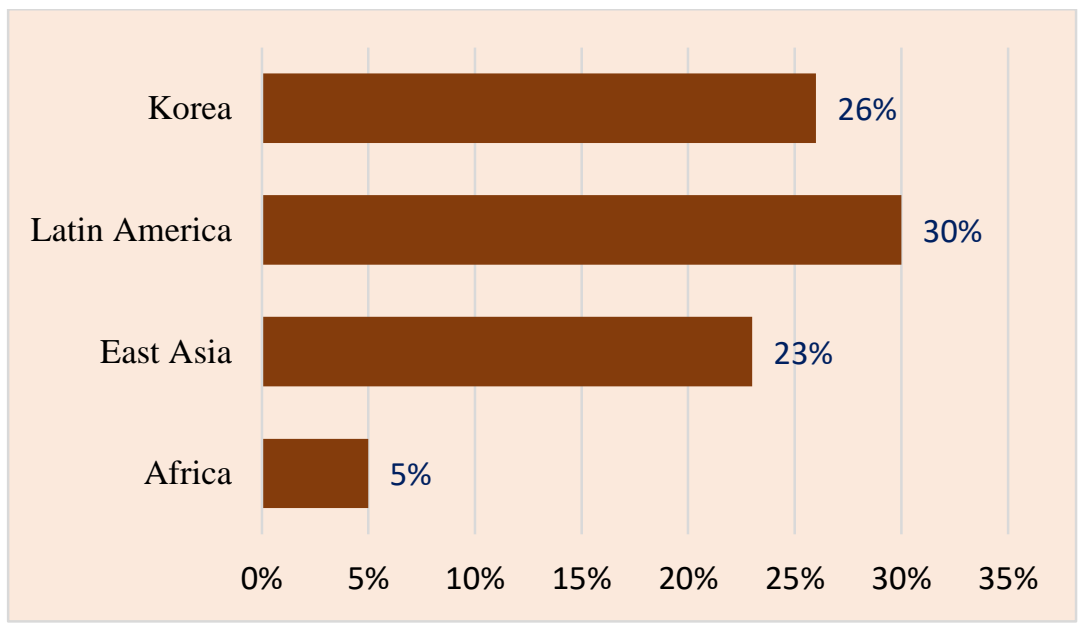

Fig. 6. Total tertiary enrollment in Africa and other countries

Based on Fig. 6, sub-Saharan Africa's overall tertiary education enrollment rate is around 5\%, compared with 23\% in East Asia and 30\% in Latin America. In Korea, 26\% of those over 15 have higher education, in Ghana less than $2 \%$.

It can be seen that Africa is seriously lagging behind in higher education due to restrictions on enrollment, inadequate employee skills and employer requirements, low retention of skilled workers, limited access to ICT and literacy.

The Bank should support the sector in ways that complement the efforts of partners, many of which focus on primary education, general education support, and scholarships for higher education [19].

We recommend that the Bank focus on vocational training, higher education, and science and technology. Higher education, will help Africa close the knowledge and technology gap, adapt, and use modern equipment and processes particularly in science and technology. That will allow Africa to link into global supply chains [20].

The Bank has already developed some experience and capacity in these areas. The analysis of the Bank's education portfolio indicates that while lending has been fairly scattered, technical and vocational training and skills development have been the largest areas of concentration, accounting for roughly $37 \%$ of education lending, with an additional $10 \%$ going to higher education. It is clear, though, that the Bank will have to build internal capacity and expertise to play a meaningful role in these more specialized areas of the education sector.

The economic costs of Africa's scarce reserves and poor infrastructure are considered significant for the continent, as well as the magnitude of the potential consequences of resolving the problem. Infrastructure investment in Africa and around the world should not be dependent on financial resources. Beyond the seemingly unlimited resources from the public sector in advanced economies and central banks, institutional investors such as insurance companies, pension funds, and sovereign wealth funds have around $\$ 100$ trillion in assets under management globally.

Infrastructure affects output and productivity directly as a contribution to the production function of other sectors and as part of GDP formation. This is considered indirect by reducing operating and other costs, which allows more efficient use of conventional production resources [21].

For example, poor energy quality can lead to additional costs for firms such as unemployed workers, lost production, or damaged equipment. However, modern transport 
systems through the delivery of raw materials to producers and industrial goods to consumers could cheaply and fast increase the competitiveness of production.

\section{The discussion of the results}

Good infrastructure indirectly by reducing transaction and other costs, allowing a more efficient use of conventional productive inputs can also raise TFP. It does this by being of production for virtually all goods and services generated by other sectors. In addition, it can affect the durability of private capital, the adjustment costs of investment and the demand for and supply of - health and education services. The firms face additional costs (buying power generators, for instance) and struggle to adopt new technologies if transport, electricity, or telecom services are absent or unreliable. The effective size of labor markets effect on the better transport [22].

More efficient use of productive inputs such as land, labor, and physical capital assets fosters lowering transaction costs, infrastructure, which translates into higher TFP, and expands the production frontier and profitable investment opportunities [23].

For example, for economic prosperity which greater reducing the cost of broadband internet could foster the development of ecommerce and a digital economy also the greater availability and reliability of infrastructure is poised to develop human capital through improved education and health services, which should foster greater economic prosperity. Finally, there has been a disproportionate focus on economic rather than social infrastructure, contributing to the high levels of exclusion, which have characterized African growth over recent decades [24].

The impact of investment is receiving significant support globally and in sub-Saharan Africa. Unlike ordinary investors, influential investors not only seek financial returns, but also have tangible, positive social and environmental consequences. In recent years, the region has seen an increase in the number of investments, especially in the infrastructure of education and agriculture. This study was aimed at identifying the main barriers and opportunities that investors face in these sectors. As the public finance gap in South Africa is likely to grow in the future, innovative transaction structures and government support will become even more important [25].

In Sub-Saharan Africa, private investment in core power and transport infrastructure has been limited to only $\$ 51$ billion over the last 25 years (Fig. 7).

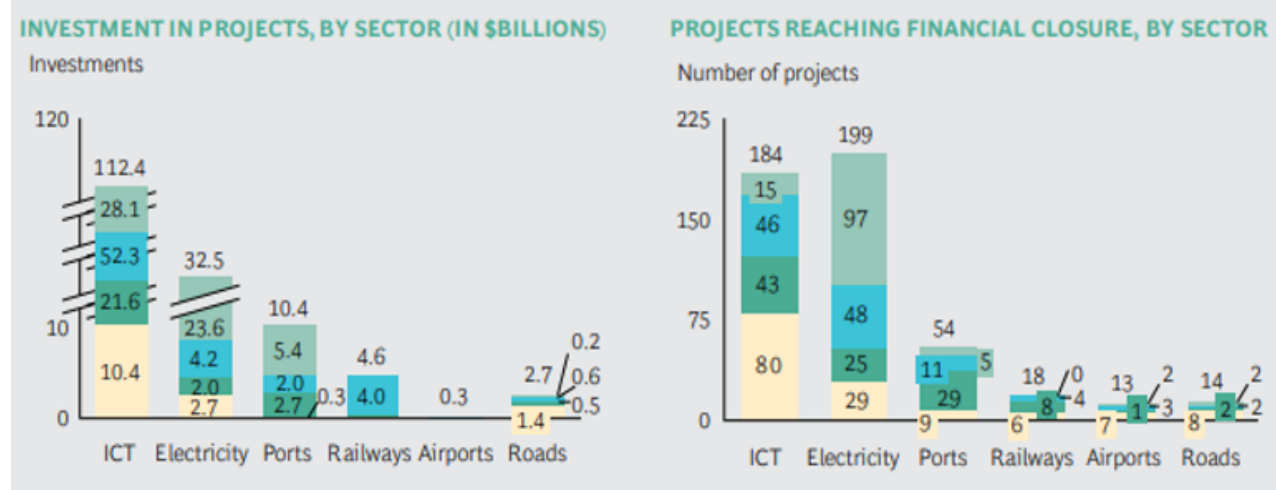

Fig. 7. Private Investment in Infrastructure in Sub-Saharan Africa, 1999-2019

Many transformational projects have enormous economic potential across the continent projects valued at \$50 million or above were worth \$324 billion in 2018 . 


\section{Conclusions}

The South African impact-investment market needs more investors across the risk/return spectrum, especially angel investor and venture capitalists, to ensure more lifecycle support for small and medium-sized social enterprises. Without an increase in angel investors and venture capitalists, the impact investment market will remain small and the competition to invest in the same later-stage entities will continue. Furthermore, more engagement is required from financial institutions, research and service providers, educators and policy makers to increase the lifecycle support of social enterprises and impact businesses in South Africa [26].

There are more barriers than opportunities for exposure now investments in infrastructure sectors in the South Africa. Nevertheless, the authors are still optimistic about the future prospects in this area. The authors of the study believe that an effective and innovative transaction structure offers endless possibilities for creating impact. The increased attention of the Bank and the government to this responsible investment strategy (through the national task of strength) is also a positive development [27].

\section{References}

1. A.S. Nechaev, O.V. Antipina, Journal of Advanced Research in Law and Economics, 7(3), 561 (2016)

2. B. Boland, Journal of Corporate Citizenship, 46, 3 (2012)

3. A.S. Nechaev, D.A. Antipin, O.V. Antipina, Journal of Mathematics and Statistics, 10(4), 443 (2014)

4. J. A. Brickley, C.W., Jr. Smith, J.L. Zimmerman, Managerial economics and organizational architecture (NY: McGraw-Hill Irwin, 2001)

5. Y. Barykina, IOP Conference Series, 667(1), 012011 (2019).

6. Y. Barykina, IOP Conference Series, 667(1), 012012 (2019).

7. N.V. Kretova, G.I. Khokhlova, A.A. Kretova, Yu A. Khokhlova, IOP Conference Series, 880(1), 012096 (2020).

8. G. Khokhlova, N. Kretova, V. Sergeev, MATEC Web of Conferences, 212, 08019 (2018)

9. A. Nechaev, A. Prokopyeva, Economic Annals-XXI, 5-6, 72-77 (2014).

10. M. Hirschey, J.L. Pappas. Managerial economics (TX: The Dryden Press,1996).

11. A. Nechaev, A. Rasputina, IOP Conference Series, 421(3), 032010 (2020).

12. A. Nechaev, T. Romanova, M. Tyapkina, MATEC Web of Conferences, 212, 09010 (2018)

13. A.S. Nechaev, A.S. Bovkun, S V Zakharov International Conf IT and QM and IS, 556 (2018)

14. A. Nechaev, O. Antipina, Economic Annals-XXI, 1-2(1), 73 (2014)

15. C.T. Horngren. Cost accounting: A managerial emphasis (NJ: Prentice Hall,1972).

16. P. Kotler, G. Armstrong. Principles of marketing (NJ: Pearson Prentice Hall, 2010).

17. P.R. Milgrom, J. Roberts. Economics, organization \& management (NJ: Prentice Hall, 1992)

18. A.S. Nechaev, S.V. Zakharov, A.O. Troshina International Conf IT and QM and IS, 552 (2018) 
19. E.J. Mishan. Cost-benefit analysis (NY: Praeger,1976)

20. A.S. Nechaev, S.V. Zakharov, Y.N. Barykina, M.V. Vel'm, O.N. Kuznetsova, Journal of Sustainable Finance and Investment, (2020)

21. W.F. Samuelson, S.G. Marks. Managerial economics (NJ: John Wiley \& Sons, 2010)

22. M. Tyapkina, Y. Mongush, E. Ilina, IOP Conference Series, 667(1), 012105 (2019)

23. S.V. Zakharov, Actual Problems of Economics, 166(4), 198 (2015)

24. S.V. Zakharov, A.S. Bovkun, K.O. Vasiliev. International Conference IT and QM and IS, 32, 8085754 (2017)

25. S.V. Zakharov, A.O. Troshina, A.U. Lobova, International Conference IT and QM and IS 601, 8085895 (2017)

26. S. Zakharov, A. Shaukalova, IOP Conference Series, 667(1), 012108 (2019)

27. I. Zedgenizova, I. Ignatyeva, European Research Studies Journal, 20(4), 578 (2017). 